\title{
Quando o humor azeda: o episódio Rushdie em retrospectiva
}

\author{
KANAVILLIL RAJAGOPALAN
}

\begin{abstract}
“ ‘Oh, os meus sapatos são japoneses', cantou Gibreel, traduzindo a velha canção para inglês em sinal de deferência semiconsciente pela nação anfitriã que subia ao seu encontro, 'e as calças inglesas, o que é que julgam? Na cabeça, um vermelho chapéu russo; no meio de tudo isto um coração indiano' “ (1).
\end{abstract}

Salman Rushdie, Os versículos satânicos

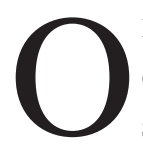
ROMANCE OS VERSÍCULOS SATÂNICOS DE SALMAN RUSHDIE começa com um estrondo. Isso, na verdade, num sentido muito literal. A choradeira (2) se faz presente, não tanto no fim do livro - embora, por seu completo contraste com o cataclisma da abertura, o final do romance também se possa descrever dessa maneira. O verdadeiro anticlímax aparece ao cabo de uma série de acontecimentos da vida real: a proibição do livro pelo governo indiano, o protesto de Bradford, a declaração do fatwa pelo aiatolá Khomeini do Irã, a gritaria e condenação da sentença de morte por parte da mídia ocidental, o abrupto desaparecimento de Rushdie em seu esconderijo, a patética tentativa do escritor, nascido na Índia, de retratar tudo e redefinir-se como um piedoso e devoto muçulmano... Pois bem, até este momento, o drama ainda se arrasta. Mas nisso tudo há uma coisa que parece bastante indiscutível: ao longo de todo o episódio, fatos e ficção envolvendo Salman Rushdie e sua malfadada obra maior estão irrecuperavelmente misturados (3).

Há um aspecto importante de Os versículos satânicos que, até onde me é dado ver, parece não ter sido apreciado adequadamente por todas as partes envolvidas na controvérsia em torno dessa obra. É o fato de que o romance apresenta todos os acessórios de um filme popular indiano, um milagre de marketing rotineiramente despejado no mercado pela gigantesca e próspera indústria cinematográfica de Bombaim. O segredo de um filme popular indiano e seu incrível sucesso consiste essencialmente em sua capacidade de faturar em cima de todas as novidades concebíveis que estejam em voga e, ao mesmo tempo, manter-se 
fiel à fórmula que provavelmente remonta aos tempos da alquimia da arte cinematográfica - os filmes mudos. Como alguém tipo Baudrillard poderia descobrir, para seu gáudio pessoal, qualquer originalidade existente num filme indiano, em oposição a qualquer outro escolhido ao acaso? A resposta está em sua afirmação singular e incansável de um distante original originário, demonstrando que sua própria essência é sua capacidade de ser muitas e muitas vezes reproduzido (4).

O gesto um tanto surrealista de Gibreel Farishta de cantarolar uma cantiga de um filme popular falado em Hindi - enquanto é arremessado em direção ao solo depois que o Boeing da Air India no qual está viajando na improvável companhia de Saladin Chamcha explode em chamas em conseqüência de uma bomba plantada por terroristas, minutos antes de sua programada aterrissagem no aeroporto Heathrow de Londres - não é de forma alguma apenas a fantástica cena de abertura de um romance bizarro. Sua letra, que soa bastante simplista, capta todo o etos de uma nação na encruzilhada da história. A referência aos sapatos japoneses sinaliza a necessidade desesperada de a Índia recém-independente invocar uma nação não-ocidental como modelo de comportamento depois da traumática experiência colonial, enquanto o chapéu russo vermelho aponta para o transe de uma nação jovem, inexperiente nas negociações diplomáticas de capa e espada da era da Guerra Fria e, ao mesmo tempo, forçada a tomar posição pelas mais diversas razões, dentre as quais, a não menos importante, o fato de seu arqui-inimigo, o Paquistão, se apressar a juntar-se à Organização do Tratado do Sudeste Asiático.

As outras duas nações mencionadas na cantiga - Inglaterra e Índia - constituem, do ponto de vista psicológico, o par de opostos absolutos que ocupa o centro da esquizofrenia cultural, que é, em última análise, o próprio romance de Rushdie. "Digna Londres, a capital de Vilayat" (5), exclama Gibreel, quando de repente percebe que está na rota de uma violenta colisão frontal com o poderoso Outro em relação ao qual e a mais ninguém sabe como definir-se a si próprio.

Ocorre estar a reação instintiva de Gibreel em perfeita consonância com o que se poderia chamar de a Gestalt cultural, geralmente característica da personalidade da maioria dos cidadãos indianos pós-coloniais (entre eles, obviamente, o presente autor), aos quais Rushdie com justeza e também com provocação se refere como "os filhos da meia-noite"; além disso, fato bastante surpreendente, muitos, senão a maioria dos cidadãos britânicos do pós-império. Bharate Vilayat - ou, se você preferir, a Índia pós-colonial e a Grã-Bretanha pós-imperial - constituem, por assim dizer, câmaras mútuas de ressonância sentimental e emocional.

A Grã-Bretanha moderna, "titã exausto" como já foi descrita, já não se banha ao sol de sua glória imperial; precisa, de vez em quando, evocar e reviver os grandes tempos de sua soberania. Os incontáveis programas de televisão, 
seriados, documentários e até mesmo filmes de longa metragem sobre o tema dão testemunho inconfundível do profundo anseio por um passado perdido. Além disso, pode-se também pensar nas centenas de restaurantes indianos que vão se espalhando por toda a Grã-Bretanha, onde homens e mulheres do lugar, especialmente os que pertencem aos grupos dos mais idosos ou de meia-idade, sempre consideram uma experiência estranhamente rejuvenescedora, um passeio fascinante pela Alameda da Memória, o fato de dirigirem seus pedidos a garçons de belos turbantes e rubros kammarbunds, matracolejando os nomes das curiosidades culinárias orientais de sua preferência sem antes precisar conferir no menu as descrições em inglês. Quanto aos indianos contemporâneos, bem, esses precisam da Inglaterra não apenas como o sempre disponível saco de pancadas para todas as contradições e divisões que hoje molestam sua nação, mas também para poderem de vez em quando reafirmar sua própria complexa identidade independente - com o que praticamente querem dizer o que sobra depois de se haverem despojado das memórias de seu passado colonial. Um exemplo extremamente ilustrativo da experiência traumática que é essa busca desesperada de uma nova identidade está no famoso episódio de aproximadamente duas décadas atrás, durante uma demonstração de massa convocada por estudantes da Universidade de Delhi em protesto contra a continuação do uso do inglês na Índia pós-colonial: no meio de milhares de contestadores gritando apaixonadas palavras de ordem estava um entusiasmado participante empunhando um cartaz que dizia: Down with English (exatamente naquela mesma língua que se propunha denunciar!). Talvez se procure em vão um exemplo melhor da relação complexa entre a Grã-Bretanha e suas ex-colônias nos aproximadamente 50 anos depois da Segunda Guerra Mundial.

Não pretendo insistir mais neste ponto. Mas poder-se-ia argumentar que aparentemente muita coisa do que acontece no mundo de Os versiculos satânicos só faz sentido se você compartilha com seu autor do trauma de estar cortado de suas raízes, de ser um eterno migrante, um ser sem identidade clara, produto da diáspora pós-colonial experimentada pela Índia e pelo Paquistão. AI 420, o número que identifica o jato da Air India cuja explosão propicia o estrondo com que Rushdie abre sua narrativa, pode não significar nada para um leitor que não tenha sido criado dentro do etos específico de que estivemos falando. Mas ninguém familiarizado com aquele etos deixará de notar a inconfundível referência a um campeão de bilheteria de todos os tempos da indústria cinematográfica da Índia. Sri 420 - a história de um vagabundo cuja vida moral impoluta se exalta de modo a compensar amplamente a penúria material que o Destino lhe reservara.

Da mesma forma, somente alguém que adquiriu algo mais do que um conhecimento superficial acerca do ambiente sócio-cultural do qual Rushdie retira os ingredientes de seu pretenso mundo de ficcionalidade factual pode ser levado a ver a lógica de Gibreel Farishta (o sobrenome deste protagonista em 
hindi/urdu quer dizer anjo, exatamente como o prenome denomina um membro famoso da espécie) repentinamente desenvolver uma auréola depois de aterrissar são e salvo em solo inglês - existe ainda mais uma famosa canção de cinema que ele não teve tempo de cantarolar durante sua queda livre, mas que certamente deve ter estado em sua cabeça o tempo todo; a canção diz Farishtõn ki nagari me mãe, aa gaya bu me mãe (À terra dos anjos, acabo de chegar). Não se deve estranhar se a angélica cidade de Londres exerce o efeito exatamente oposto sobre Saladin Chamcha (cujo sobrenome, a propósito, significa bajulador), que se metamorfoseia num sátiro, meio homem, meio bode, com chifres, hálito fétido, pés fendidos e um falo de proporções monstruosas.

Mas tudo isso é completamente irrelevante, se o que estamos procurando for uma resposta à pergunta: por que o livro de Rushdie irritou a tantas pessoas e em tal grau que as fez desejarem sua morte. Talvez devêssemos, antes de arriscar qualquer hipótese, deixar que o próprio Rushdie expusesse seu caso. Numa nota distribuída à imprensa, ironicamente intitulada De boa fé (6), Rushdie caracteriza seu romance com as seguintes palavras: "Se Os versículos satânicos chegam a ser alguma coisa, eles são a visão de mundo através dos olhos de um migrante. Foram escritos a partir da própria experiência de desenraizamento, desligamento e metamorfose (lenta ou rápida, penosa ou agradável) que constitui a condição do migrante, e da qual acredito ser possível derivar uma metáfora para toda a humanidade".

E prossegue acrescentando: "Os versículos satânicos celebram a hibridez, a impureza, a entremesclagem, a transformação que resulta de uma combinação nova e inesperada de seres humanos, culturas, idéias, política, filmes, canções. Exulta na mestiçagem e teme o absolutismo do Puro. Mistura, mixórdia, um pouco disso e um pouco daquilo, é assim que o novo surge no mundo. É a grande possibilidade que a migração em massa oferece ao mundo, e eu tentei abraçá-la. Os versículos satânicos são pela mudança-por-fusão, mudança-por-combinação. É uma canção viva dedicada aos nossos eus de vira-latas".

Tendo assim sublinhado o apelo universal de seu romance, Rushdie nos convida a ponderar sobre a seguinte asserção genérica: “Através da história da humanidade, os apóstolos da pureza, aqueles que asseveraram possuir uma explicação total, criaram desordem entre os simples homens misturados. Como milhões de pessoas, sou um filho bastardo da história. Talvez todos sejamos, negros, pardos e brancos, vazando um no outro, como disse uma vez uma de minhas personagens, como sabores quando se cozinha".

A mera força da retórica de Rushdie não deve permitir que desviemos nossa atenção do notável feito argumentativo que ele consegue nos excertos citados. Num rápido golpe, ele vira a mesa contra seus acusadores. Aqueles que com absoluta sinceridade o denunciavam como parte de uma conspiração 
satânica (7) contra o Islã e até o comparavam com nada menos do que o caso paradigmático do Mal Encarnado, isto é, Adolfo Hitler, de fato o acusavam, a ele, Salman Rushdie, de um ponto de vista que era a própria marca registrada da ideologia nazista - pureza étnica, cultural, religiosa, ou seja lá o que for! São eles que implicitamente reivindicam ter uma explicação total, não Rushdie. São eles que, em nome daquela explicação total, condenaram Rushdie à morte pela única razão de que ele não estava à altura de seus padrões de pureza e compromisso total com uma interpretação definitiva (8).

Mas acontece que, seja qual for a força retórica e o mérito lógico da jutificativa post hoc de Rushdie, seu caso não tinha salvação, como de fato a seqüência de acontecimentos daí para frente claramente mostrou. O que deu errado para ele? Como é que tais repúdios logicamente inatacáveis de Rushdie segundo os quais ele não poderia, com toda justiça, ser acusado de blasfêmia porque, em primeiro lugar, nunca fora um verdadeiro crente, não produziu absolutamente qualquer efeito em suas sempre crescentes fileiras de acusadores?

Mulheres mulçumanas exibem fotografia do aiatolá Khomeini em cerimônia religiosa

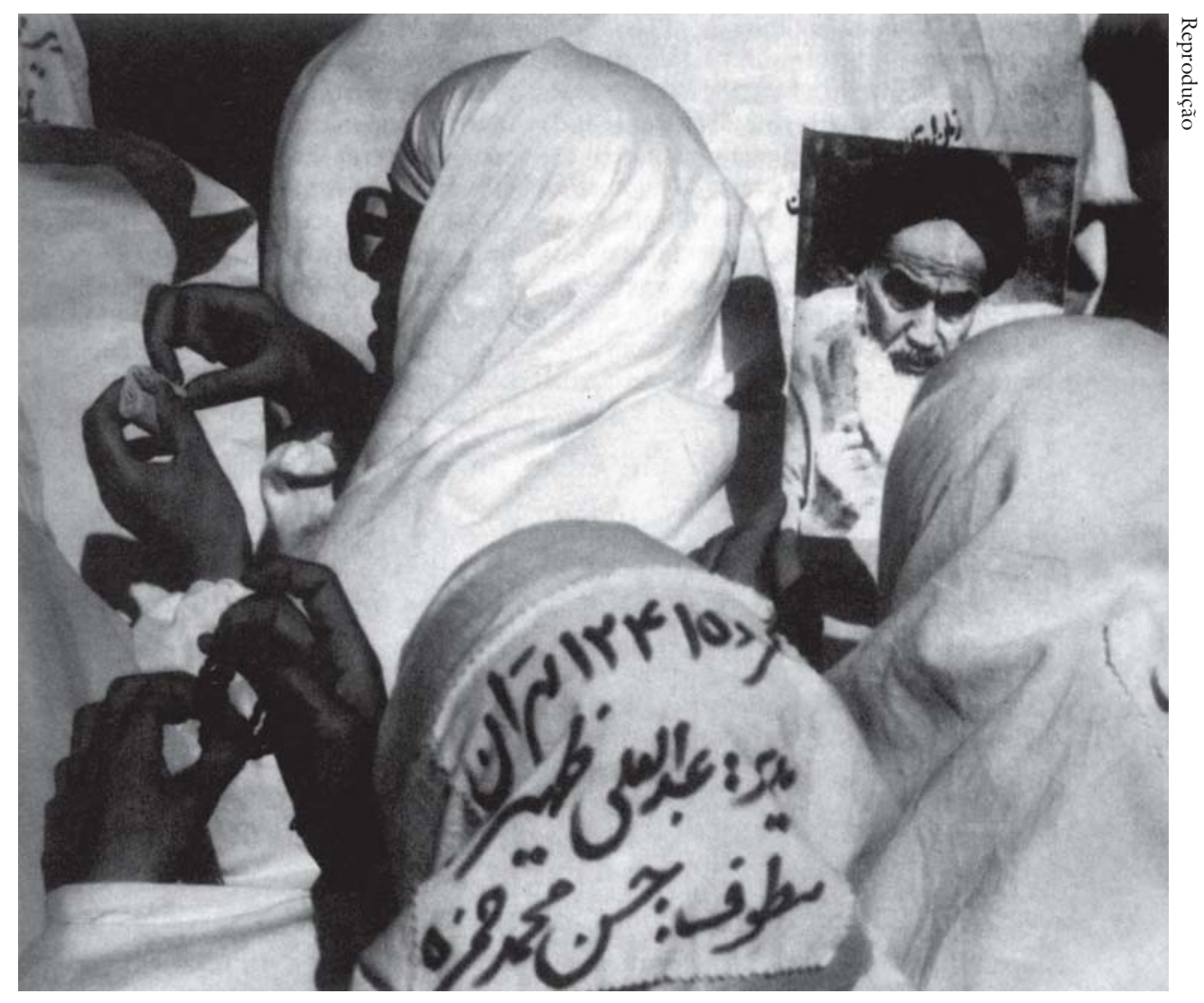

A resposta a essa indagação está muito provavelmente no estilo inimitável de Rushdie e, em especial, no uso que faz da ironia como um meio para conse- 
guir seus efeitos. "Ironia?", exclama Malise Ruthven, o autor de Satanic affair: Salman Rushdie and the Rage of Islam (9), "ou algo mais sinistro? Ironia parece ser um termo fraco demais para aplicar à ficção de Os versículos satânicos. Parece que o romance surpreendeu seu autor, ameaçando-lhe a vida e transformandolhe a existência numa espécie de farça horripilante vivida por personagens saídas da imaginação dele, personagens cujos sonhos, do interior dos recipientes de suas identidades, observam e investigam a narrativa ficcional de suas vidas."

Já observamos que nos Versículos satânicos o leitor fica totalmente perdido quando se trata de traçar uma linha entre fato e ficção. Igualmente importante sublinhar é que a própria vida de Rushdie está envolvida e insoluvelmente entretecida com o drama assustador que se desenrola no romance. Assim, quando ele diz logo no início da obra, precisamente na frase de abertura, "Para se nascer de novo ... é preciso primeiro morrer. Ho ji! Ho ji! Para se poisar na terra acolhedora, é preciso primeiro voar. Tattaa! Takathun! Como tornar um dia a sorrir, sem se chorar primeiro?" (10), suas palavras se revelam impregnadas de forte ironia dramática, isto é, dessa ironia que inconscientemente calha ter como alvo sua própria fonte locucionária. Coincidência ou não, todas as celebridades da vida real a quem Rushdie dera atenção especial em dois de seus romances anteriores, os igualmente polêmicos Midnight's children e Shame - a saber, Indira Gandhi, Zulfikar Ali Bhutto e o General Zia ul Haqq - tiveram suas vidas truncadas de modo brutal e violento.

Assim que as comportas de sua frenética e endriabrada imaginação se abrem, a ironia ultrapassa o mundo ficcional de Rushdie e, não encontrando obstáculos pelo caminho, rápida invade e inunda sua própria vida, tanto a privada quanto a pública. A própria Margaret Thatcher, às custas de quem ele afiara à vontade seu gênio satírico, viria depois em seu auxílio defendendo-lhe a liberdade de expressão e ordenando que a Scotland Yard o protegesse vinte e quatro horas por dia. Se essa ironia não bastar, considere-se o que estava reservado para aquele que escrevera “... andem, sacanas, venham cá buscar-nos", ou então, “oh, meu Deus, oh, meu Deus, eles vão mandar os comandos, fodam-se, os cabrões dos americanos, os filhos da puta dos ingleses" (11) - até mesmo George Bush, o então presidente dos Estados Unidos, sentiu a necessidade premente de tomar um pouco do tempo de sua agenda lotada para considerar a ameaça iminente - embora vindo de longe - contra um precioso item da Primeira Emenda Constitucional. Não faz muito tempo, exatamente em novembro de 1993, Rushdie foi visto numa visita relâmpago à Casa Branca para encontrar-se com o presidente Clinton, como parte do esforço supremo do escritor, queimando o último cartucho para forçar o Irã a suspender a sentença de morte que lhe foi imposta.

Se a ironia é um instrumento extremamente eficaz à disposição de um escritor, é também, como vem se vê, o mais difícil de manejar. Na realidade, 
nunca se sabe quando o tiro vai sair pela culatra. O caso de Rushdie é um exemplo ímpar de ironia que atacou às cegas, de humor que azedou cedo demais. $\mathrm{O}$ homem que evidentemente se deliciava atacando todo mundo quando se tratava de deixar sua mordaz ironia correr solta não deveria, dentro do melhor espírito esportivo, ofender-se ao ser lembrado que seu próprio nome pede um trocadilho que parece entretecido com o engenhoso enredo que vai se desenredar em seu romance: "Rushdie invadiu [rushed in] os campos que anjos (inclusive o filho de sua mente, Gibreel Farishta) temiam pisar"! (12).

Alarmado com a inesperada reação à publicação de seu livro e assustado com as sombrias perspectivas futuras que no fim o forçaram a esconder-se, Rushdie tentou todos os meios disponíveis para salvar sua pele. O mesmo homem que, numa ocasião anterior, tão seguro de si afirmara, a propósito de George Orwell, que toda literatura é fatalmente política "porque o que se discute é nada menos que a situação real da vida," (13) iria insistir: "No centro da tempestade está um romance, um trabalho de ficção, que aspira à condição de literatura." (14) Mal, porém, havia assim caracterizado sua polêmica obra, foi tomado por um sentimento de auto-reprovação que o forçou a desmentir sua afirmação anterior, dizendo: "Parecia impossível, em meio a tal balbúrdia, insistir no caráter ficcional da ficção," e apressou-se a acrescentar: "Deixem-me esclarecer; não estou tentando dizer que Os versículos satânicos são 'apenas um romance' e assim não precisa ser tomado a sério, e até discutido com a mais intensa paixão. Eu não acredito que palavras sejam questões triviais."

O ponto crucial do verdadeiro, excruciante dilema de Rushdie é o seguinte: ou seu romance é uma questão séria e, neste caso, a acusação de difamar uma das religiões mais importantes do mundo tem alguma base factual e a sentença de morte decretada contra ele não é totalmente infundada, embora se possa argumentar que é exageradamente severa; ou, então, é um mero trabalho de ficção despropositada e perversa, produto de uma mente aflita, totalmente confusa, e o próprio Rushdie é "um (talvez não tão) belo anjo ineficaz, batendo as asas no vazio (15) - ou, se você preferir, um farishta extremamente fictício".

Bem se pode ver que nenhum dos dois chifres do dilema constitui um lugar de confortável descanso para alguém na situação de Salman Rushdie.

Seja como for, parece que a esta altura vale a pena perguntar se e em que medida o transe particular de Rushdie se presta a generalizações. Parece que se pode levantar a discussão de não ser a série de infortúnios na vida de Rushdie absolutamente acidental ou gratuita, mas parte integrante do próprio empreendimento da literatura e, de fato, de toda escrita, e um risco inevitável que fatalmente corre todo escritor - empunhador de um stylus - que escolhe a ironia como o meio de dar seu recado. 
No dia 22 de janeiro de 1989, o suplemento literário do The Times trazia interessante nota de apoio de um certo Fadia A. Faquir, romancista jordaniano usuário da língua inglesa, que se havia, ele próprio, metido em encrenca devido a alguns de seus escritos sobre o Islã e levava uma vida de exílio auto-imposto na Grã-Bretanha. "O conflito entre a literatura e o Islã”, escrevia ele, “... começou quando o Arcanjo Gabriel ditou a Maomé o seguinte versículo do Corão: 'Quanto aos poetas, o errar os acompanha. Não viste como vagueiam por todos os vales? E como dizem aquilo que não é...'”. O autor prosseguia argumentando que à medida em que o Corão era visto como tendo sido apresentado como o texto supremo e final, a escrita desde então sempre havia sido objeto de desrespeito e muitas vezes de desprezo por ser um ato de subversão. "O problema principal que o intelectual muçulmano enfrenta está no fato de que os indivíduos muçulmanos nunca lêem os textos em discussão mas aceitam o juízo de valor de seus Iamames e Ulemás" (16).

De fato, a afirmação de Faquir foi corroborada pela seguinte espantosa observação de Syed Shahabuddin, o parlamentar indiano que havia anteriormente encabeçado a exitosa campanha que levou ao banimento de Os versículos satânicos por parte do governo indiano. Numa carta ao The Times of India em 1988, Shahabuddin escreveu (17): "Você [Salman Rushdie] está magoado porque alguns de nós o condenaram sem uma audiência e pedimos o banimento de seu livro sem lê-lo. Sim, eu não o li nem pretendo ler. Não preciso atravessar um escoadouro imundo para saber o que é sujeira. Meu primeiro passo desavisado me diria em que estava pisando".

Parece que o caso de Rushdie estava completamente perdido já desde o princípio. Havia uma interpretação definitiva, inegociavelmente final, sempre já disponível e sempre pronta para ser imposta a qualquer temerária incursão contra o único texto final e supremo. E, como as palavras do parlamentar indiano tornam perfeitamente claro, não havia como autor, em tais circunstâncias, pudesse escapar às duras conseqüências de sua imprudência, pois a interpretação definitiva que ele está condenado a carregar também se identifica - como convém a todas as interpretações putativas definitivas - com a intenção autoral. Daí decorre a alegada justificativa de toda a ação retaliatória mobilizada contra Rushdie, seu romance bem como sua pessoa: a difamação não aconteceu por acidente ou inadvertência; havia um claro intuito de difamar e profanar a Fé Sagrada.

Sejamos absolutamente claros neste ponto: o que o episódio Rushdie coloca diante de nós não é um caso de interpretação em que a intenção comunicativa do autor foi deliberadamente posta de lado, a fim de abrir espaço para outra que seus sanguinários caluniadores quisessem lhe atribuir. Ao invés disso, o que temos é um caso no qual a própria necessidade de investigar o texto à procura de intenção comunicativa do autor foi totalmente dispensada, não porque se acredi- 
tasse que não haveria intenção alguma, assim esperando para ser desenterrada, mas porque seus caluniadores agiram convencidos de que, para eles, a intenção em questão sempre esteve já disponível - de fato, até mesmo antes de Rushdie sequer pensar em lançar a mão da pena.

Em outras palavras, o que o episódio de Rushdie revela não é um caso em que os cânones convencionais da interpretação foram abertamente desrespeitados; muito pelo contrário, todo o episódio envolvendo o autor e seu malfadado romance poderia simplesmente não ter tomado o rumo que tomou, se as diferentes personalidades envolvidas no caso - inclusive, até certo ponto, o próprio Rushdie assim como os inúmeros fanáticos, muitos dos quais deram suas vidas tentando defender suas conviç̧ões - não estivessem tacitamente agindo com base na suposição de que a sabedoria convencional acerca do que significa interpretar, no fim das contas, era ainda válida.

Em retrospectiva, é bastante fácil ver que foi exatamente nesse ponto que Rushdie cometeu seu fatal erro de cálculo. Fiel ao espírito da condição pósmoderna que ele acreditava ter envolvido os "filhos da meia-noite" iguais a si mesmo, condição marcada por um sentimento sem fim de dispersão e de nãopertencer, Rushdie, pelo que parece, havia esperado em vão que seus leitores contemporâneos não tivessem dificuldade alguma em chegar a um acordo com um texto cuja constante sugestão irônica por si só garantiria um fluxo interpretativo infinito.

O que Rushdie não esperava, então, era a complexa questão da política da ironia (18). De fato, um modo altamente revelador de rever o episódio Rushdie em retrospectiva é vê-lo como um exemplo fundamental da vingança da ironia contra aqueles entre seus praticantes ingênuos que, seguindo as pegadas de Thomas Mann (19), ele próprio um autoproclamado homem não-politico, cuidam de suas vidas como se não existisse um antagonismo irredutível entre ironia e política. Isso é duplamente irônico no caso de Rushdie. Pois, como seu próprio arguto comentário sobre Orwell deixa claro, ele sabia muito bem que, irônicos ou não, todos os romances trazem consigo uma dimensão política inevitável. Por outro lado, é igualmente óbvio que Rushdie só poderia evadir-se da ira de Khomeini invocando uma separação não-política de ironia e política, e foi precisamente isso que fez quando apelou para a ficcionalidade da ficção. Mas aí, depois que tudo foi dito e feito, não se pode deixar de perguntar se essa presumível separação não-política de ironia e política não é ela mesma irônica, se não for, o que seria talvez ainda mais chocante, um lance motivado por uma conveniência politica!

Quando finalmente a poeira envolvendo o episódio Rushdie se assentar, pode muito bem acontecer que continuemos a lembrar Os versículos satânicos 
como a expressão cabal da tensão dialética, irredutível, entre a política em geral de um lado e, do outro, a ironia aclamada e apregoada por pensadores de todos os naipes que de um modo geral compartilham uma persuasão pós-moderna como a figura mestre da linguagem de nosso tempo.

\section{Notas}

I Salman Rushdie, Os versículos satânicos (Lisboa, Publicações Dom Quixote, 1995) p. 17. Tradução de Ana Luísa Faria e Miguel Serras Pereira. As demais citações de Os versículos satânicos que ocorrem neste trabalho seguem essa versão portuguesa (N.T).

2 "Estrondo" e "choradeira" fazem alusão ao final do poema "The hollow men" [Os Homens Ocos] de T. S. Eliot: "This is how the world ends / This is how the world ends / This is how the world ends / Not with a bang but a whimper." [É assim que o mundo acaba / É assim que o mundo acaba / É assim que o mundo acaba / Não num estrondo mas em choradeira.] (N.T.)

3 Este trabalho foi planejado e escrito enquanto eu estava em programa de pós-doutorado na Universidade da Califórnia, em Berkeley, durante 1993. Gostaria de agradecer à Capes por me oferecer apoio (através de uma bolsa, processo 2715-92-07) ao longo de um ano de estadia nos Estados Unidos.

4 Cf. Simulations [Simulações]. New York, Semiotext (e) Inc. 1983.

5 The satanic verses. London, Viking, 1988, p. 4. A palavra vilayat, em hindi-urdu, significa Inglaterra e, por extensão, Grã-Bretanha.

6 Cf. Salman Rushdie, In good faith. UK, Granta, 1989.

7 Ver, por exemplo, S.R. Ali, The satanic conspiracy. Calcutta, Peacock Publising Co.

8 Agora, com certeza, existe algo genuinamente satânico, de fato satânico no melhor sentido miltoniano, neste ardil de Rushdie. Isso fica muito mais evidente quando se observa a Epígrafe que o autor escolheu para a sua obra, na qual se lê o seguinte excerto de The history of the devil, de Daniel Defoe: "Satã, assim relegado para uma condição vagabunda, errante, instável, não tem paradeiro certo; pois embora possua, em conseqüência da sua natureza angélica, uma espécie de império sobre os desertos líquidos e os ares, faz certamente parte do seu castigo que ele não disponha ... de qualquer lugar ou espaço fixo onde descanse a planta dos pés."

9 London, Chatto Windus, 1990, p. 11-12.

10 The satanic verses, p.3. Versão portuguesa, p. 15.

11 Id., p. 85. Ibid., p. 84.

$12 \mathrm{O}$ trocadilho repousa no famoso verso de Alexander Pope: "For fools rush in where angels fear to tread", [Pois tolos invadem campos que anjos temem pisar] Essay in criticismo, 1. 625. (N.T.). 
13 Ver Timothy Brennan, Salman Rushdie and the third world: myth of the Nation. London, Unwin, 1986, p. 64.

14 In Good Faith, p. 4.

$15 \mathrm{O}$ autor faz aqui uma alusão a uma frase de Matthew Arnold referindo-se a P.B. Shelley: "... a beautiful and ineffectual angel beating in the void his luminous wings in vain." Essays in criticism, Second Series, Shelley. (N.T.).

16 Ver L. Appignanesi and S. Marland, The Rushdie file. Syracuse University Press, 1990. p. 225-226.

17 Citado em M.A. Anees, The kiss of Judas: the affairs of a brown sabib. Kuala Lampur, Quill Publishers, p. 24.

18 Sobre essa questão, ver a excelente coleção de trabalhos The politics of irony: essays in self-betrayal, organizada por D.W. Conway e J.E. Seery. New York, St. Martin's Press, 1992.

19 Ver Reflections of a non-political man, 1917. Citado na Introdução a The politics of irony, citado.

\section{Resumo}

Este trabalho é uma tentativa de analisar retrospectivamente o episódio que envolve Salman Rushdie e seu romance Os versículos satânicos. Começo minha análise chamando atenção para o fato de que tanto o enredo da obra quanto o ambiente sócio-políticohistórico em que ela aparece estão mergulhados no meio cultural da Índia de modo a não surpreender que o romance tenha se transformado numa questão tão explosiva no cenário internacional. Em seguida argumento que isso tudo nos ensina uma lição importante a respeito de leitura e interpretação. O que quer que Rushdie ou outra pessoa fizesse com o intuito de voltar atrás ou pedir clemência aos aiotolás enfurecidos, não havia como submeter o romance a uma re-leitura - a única interpretação final e definitiva já havia sindo impingida ao malfadado romance. Essa é a enrascada pós-moderna de Rushdie. A ironia - a mesma arma que ele tão habilmente havia utilizado não apenas nos Versículos satânicos mas também em seus romances anteriores - voltou-se contra ele, produzindo um inesperado efeito bumerangue. O que temos aqui é um caso de política da ironia em ação.

\section{Abstract}

This paper is an attempt to review in retrospect the episode involving Salman Rushdie and his novel The satanic verses. I begin my analysis by calling attention to the fact that both the plot of the novel and the socio-historico-political backdrop against which it is projected are so steeped in India's cultural milieu that it is indeed surprising that the novel became such an explosive issue on the international scenario. But then I argue that there is an important lesson to be learned from all this concerning reading and interpretation. No matter what Rushdie or anybody else could possibly have done by 
way of retracing the steps or pleading with Iran's enraged ayatollahs for clemency, there was no way his novel could have been subjected to a re-reading - the one final and definitive interpretation had already been foisted upon the ill-fated novel. This is Rushdie's postmodern predicamente. Irony - the one weapon he had so skilfully wielded not only in The satanic verses but in his earlier novels as well, turned back on him, producing an unexpected boomerang effect. What we have here is a case of the politics of irony at work.

Kanavillil Rajagopalan é professor de lingüística do Instituto de Estudo da Linguagem da Universidade Estadual de Campinas (Unicamp).

Tradução de Almiro Pisetta. O original em inglês - When humor turns sour: the Rushdie episode in retrospect - encontra-se à disposição do leitor no IEA-USP para eventual consulta. 